\title{
Prevalence of Veterinary Drug Residues and Heavy Metals in Catfish Nuggets
}

\author{
Gulnihal Ozbay ${ }^{1 *}$, Balaji Kubandra Babu and Guoying Chen ${ }^{2}$ \\ ${ }^{1}$ Department of Agriculture and Natural Resources, Delaware State University, 1200 North DuPont Highway, Dover, DE 1990, USA \\ ${ }^{2}$ USDA-ARS-ERRC, 600 E. Mermaid Lane, Wyndmoor, PA, USA 19038, USA
}

\begin{abstract}
Seafood such as catfish can sometimes become contaminated with chemicals and heavy metals at levels which would harm human health. There has been renewed interest by the USDA Food Safety Inspection Service (FSIS) in determining the incidence and prevalence of potentially harmful contaminants in catfish products. Many studies of retail catfish have focused on the fillet portion of the fish. Catfish nuggets are the fatty belly flap of the fish which is removed during processing and are sold as a separate product. Retail catfish nuggets from domestically raised catfish were collected in New Jersey, Pennsylvania, New York and Delaware and then tested for the presence of chemical contaminants including the heavy metals arsenic, lead, mercury, and cadmium. Of the 24 nugget samples tested none tested positive for the presence of arsenic or lead. Cadmium was detected in nine samples, but the levels were well below the regulatory action levels indicated for seafood. Mercury was detected in one catfish sample, but again the concentration was well below the U.S. FDA action limit for methyl mercury in fish. In addition, the presence of veterinary drug residues including malachite green, gentian violet and chloramphenicol in domestic catfish nuggets was also determined. One sample tested positive for the presence of gentian violet, however, given the low level detected $(1.1 \mathrm{ppb})$ it is theorized to have occurred due to post-process contamination.
\end{abstract}

Keywords: Domestic catfish; Catfish safety; Catfish nuggets; Heavy metals; Gentian violet; Malachite green chloramphenicol; Drug residues; Cadmium; Lead; Mercury; Arsenic

\section{Introduction}

In the past twenty years, there has been an extensive commercialization and increased consumption of seafood produced by aquaculture. According to the New York Times [1], every year about 6.6 million tons of seafood is imported into the U.S. from 160 different countries. Catfish production continues to dominate the domestic aquaculture industry in the US, representing $69 \%$ of fish sales in 2005 [2].

According to the National Fisheries Institute [3], catfish ranked number six of the top ten sea foods consumed in the United States in 2007, with 395 gram consumed per person. Fillets were the most consumed form of catfish (59\% of total sales), followed by the whole fish $(21 \%)$ and the remaining $20 \%$ sales were in the form of nuggets, steaks and other further processed products [4]. The United States Department of Agriculture (USDA) defines nuggets as "small fillets cuts from below the rib section of the fish and usually includes weight of breading and added ingredients" [4]. The nuggets are popular and it is important to ensure the quality and safety of catfish nuggets consumed by the American public.

As the aquaculture industry grows, the use of unapproved and/ or the misuse of chemicals and treatment strategies administered to aquaculture seafood is also growing [5]. Malachite green (MG) is a toxic chemical substance that is used to treat bacterial and fungal infections in fish, most frequently used for treating aquarium fishes [6]. MG is a known mutagen and has been banned in the U.S. [7]. Gentian Violet (GV) has also been known to cause cancer and affect the urinary bladder, ovaries and uterus in mice [8]. In another study, leuco malachite green was found to cause visceral abnormalities and embryo lethality at a dosage of $160 \mathrm{mg} / \mathrm{kg} /$ day in lab rats [9]. Chloramphenicol is known to cause bone marrow depression [10]. MG, GV and CAP are given zero tolerance in the US and are not permitted in fish products [5]. Heavy metals, at sufficient levels, have been associated with decreased intelligence and development, heart disease, and other harmful effects [11].

Previous studies have focused on heavy metal and chemical residue detection in catfish fillets. Our primary objective in this study was to determine the prevalence of heavy metal contamination including As, $\mathrm{Pb}, \mathrm{Hg}, \mathrm{Cd}$ and drug residues including $\mathrm{MG}, \mathrm{GV}$ and $\mathrm{CAP}$, in retail catfish nuggets collected from New York, New Jersey, Pennsylvania, and Delaware.

\section{Materials and Methods}

\section{Instrumentation}

A Perkin Elmer Atomic Absorption Spectrometer (AAnalyst 600) and a Flow Injection Mercury System (FIMS 100) with WinLab 32 interface was used for detecting heavy metals in the fish samples (Perkin Elmer, Shelton, CT). BioTek ELISA reader (BioTek Instruments, Winooski, VT) was used to measure the absorbance values in ELISA screening experiments for detecting the presence of veterinary drug residues.

\section{Chemicals and reagents}

The reagents from BioControl TRANSIA Plate Chloramphenicol Test Kits (BioControl, Bellevue, WA) were used to screen for presence of CAP in fish samples. Similarly, the reagents and ELISA wells from

*Corresponding author: Gulnihal Ozbay, Department of Agriculture and Natura Resources, Delaware State University, 1200 North DuPont Highway, Dover, DE 19901, USA, Tel: 3028576476; E-mail: gozbay@desu.edu

Received August 17, 2012; Accepted September 28, 2012; Published October 07, 2012

Citation: Ozbay G, Babu BK, Chen G (2013) Prevalence of Veterinary Drug Residues and Heavy Metals in Catfish Nuggets. J Food Process Technol S11-005. doi:10.4172/2157-7110.S11-005

Copyright: (C) 2013 Ozbay G, et al. This is an open-access article distributed under the terms of the Creative Commons Attribution License, which permits unrestricted use, distribution, and reproduction in any medium, provided the original author and source are credited. 
BiooScientific Malachite Green / LMG ELISA Test Kits (BiooScientific, Austin, TX) were utilized in MG/GV identification. Solvents like n- hexane, acetonitrile, dichloromethane, ethyl acetate and HPLC grade water were procured from Fisher Scientific, Savannah, GA. The calibration stock solutions $(\mathrm{Hg}, \mathrm{Pb}, \mathrm{Cd}$ and $\mathrm{As}, 1000 \mathrm{ppm})$ were purchased from SCP Science, Champlain, NY. The acids and chemicals used in the heavy metal testing like nitric acid, hydrochloric acid, sulfuric acid, potassium permanganate, potassium persulfate, L-ascorbic acid, potassium iodide and HPLC grade water were purchased from Fisher Scientific, Savannah, GA.

\section{Sample collection and preparation}

A total of 24 retail catfish nugget samples (1 sample was 5 individual nuggets) were screened for the presence of veterinary drug residues and heavy metal contaminants. The individual catfish nuggets were finely blended for about $15 \mathrm{~min}$ at room temperature using a laboratory blender (Kitchenaid, New York) to yield a paste. Care was taken to avoid contamination of fish samples with environmental contaminants by rinsing the blender, knife and other appliances with deionized water once they were cleaned under running water with phosphate free laboratory cleaner. The blended samples were then stored at $-20^{\circ} \mathrm{C}$ in freezer for about 1-2 months until they were tested for the chemical contaminants.

\section{Heavy metal analyses}

The concentrations of $\mathrm{As}, \mathrm{Cd}$ and $\mathrm{Pb}$ were determined using the Perkin Elmer Atomic Absorption Spectrometer (AAnalyst 600). The concentration of $\mathrm{Hg}$ in the fish samples was determined using the Perkin Elmer Flow Injection Mercury System (FIMS 100).

Lead and cadmium analysis: The $\mathrm{Pb}$ and $\mathrm{Cd}$ analysis was performed according to USDA- FSIS CLG-TM1.01procedures [12]. For the analysis, $15 \pm 0.1 \mathrm{~g}$ of the catfish sample was weighed into $50 \mathrm{ml}$ vycor crucibles (Corning, Lowell, MA). Then, $7.5 \mathrm{ml}$ of $6.67 \%$ $\mathrm{Mg}\left(\mathrm{NO}_{3}\right)_{2}$ was added to all samples and mixed well using spatulas for about $5 \mathrm{~min}$. The samples were then heated in the muffle furnace at $95^{\circ} \mathrm{C}$ for about $360 \mathrm{~min}$. The second step was to ash the samples in the furnace at $550^{\circ} \mathrm{C}$ for $960 \mathrm{~min}$. The samples were then taken out of the furnace and allowed to cool to room temperature. In the second ashing step, $2 \mathrm{ml}$ of $50 \% \mathrm{HNO}_{3}$ was added to samples and heated at $550^{\circ} \mathrm{C}$ for $60 \mathrm{~min}$. The last step was to dissolve the ash with $15 \mathrm{ml}$ of $1.0 \mathrm{~N}$ $\mathrm{HCl}$ and transferred to $15 \mathrm{ml}$ propylene centrifuge tubes and stored until further analysis using the AAS 600. The matrix modifier used for lead analysis was a mixture of $1 \%$ ammonium phosphate and $0.06 \%$ magnesium nitrate. For cadmium analysis, a solution of $1 \%$ palladium and $0.06 \%$ magnesium nitrate was used as the matrix modifier. Spiked catfish control samples (50-100 ppb of $\mathrm{Pb}$ and $\mathrm{Cd}$ ) were used in every sample set to validate the results obtained from lead and cadmium analysis.
Arsenic analysis: The concentration of as in catfish samples was determined following the USDA-FSIS CLG-ARS1.04 protocol [13] The homogenized nugget samples were weighed $(5 \pm 0.1 \mathrm{~g})$ into $50 \mathrm{ml}$ Vycor crucibles. Each analysis set contained samples, controls, fortified control and reagent blank. Then, $4 \mathrm{ml}$ of $50 \% \mathrm{MgNO}_{3}$ was added to each sample and mixed well. The samples were then dried and ashed in Thermolyne Muffle Furnace (Thermo Fisher Scientific, Waltham, MA).

The ashing steps involved three levels of heating for different periods of time. In the first step, the samples were dried at $100^{\circ} \mathrm{C}$ for $360 \mathrm{~min}$, followed by heating at $150^{\circ} \mathrm{C}$ for $360 \mathrm{~min}$ and then finally ashed at $500^{\circ} \mathrm{C}$ for about $480 \mathrm{~min}$. At the end of step 4 , the samples are taken from oven and allowed to cool in the room temperature. Then $3 \mathrm{ml}$ of $50 \% \mathrm{HNO} 3$ was added to all crucibles. The samples were then heated for $60 \mathrm{~min}$ at $550^{\circ} \mathrm{C}$, followed by cooling at room temperature. To each sample, the following three solutions were added: $10 \mathrm{ml}$ of $4.5 \mathrm{~N} \mathrm{HCl}, 35 \mathrm{ml}$ of $10 \% \mathrm{HCl}$ and $5 \mathrm{ml}$ of $10 \%$ potassium iodide / ascorbic acid solution. The matrix modifier used in arsenic analysis was $0.1 \%$ palladium solution with $0.06 \%$ magnesium nitrate. A mixture of $15 \mu \mathrm{l}$ of matrix modifier and $20 \mu \mathrm{l}$ of the sample solution was injected into the AAS 600 (by auto sampler) for arsenic analysis. The method was validated by spiking the control catfish sample with known concentrations of arsenic standards and the analysis was done in duplicate to validate the analytical method.

Mercury analysis: Mercury analysis was conducted according to the USDA-FSIS CLG-MERC1.00 protocol [14]. For analysis, 0.3 $\pm 0.1 \mathrm{~g}$ of the catfish samples was weighed in $300 \mathrm{ml}$ Biochemical Oxygen Demand (BOD) bottles. To each bottle, $1 \mathrm{ml}$ of $70 \% \mathrm{HNO}_{3}$ and $4 \mathrm{ml}$ of $\mathrm{H}_{2} \mathrm{SO}_{4}$ was added and mixed well. The BOD bottles were then incubated in a water bath set at $80 \pm 5^{\circ} \mathrm{C}$ for $30 \mathrm{~min}$. The bottles were then taken from the water bath and allowed to cool. To the BOD bottles, the following two solutions were added: $15 \mathrm{ml}$ of $\mathrm{KMnO}_{4}$ and $8 \mathrm{ml}$ of $5 \% \mathrm{~K}_{2} \mathrm{~S}_{2} \mathrm{O}_{8}$. The BOD bottles were then incubated in water bath for $90 \mathrm{~min}$ at $30 \pm 5^{\circ} \mathrm{C}$. Then, $10 \mathrm{ml}$ of the solution from the BOD bottles were transferred to $15 \mathrm{ml}$ polypropylene centrifuge tubes. To each centrifuge tube, $750 \mu \mathrm{l}$ of $12 \%$ hydroxylamine solution was added. The solution was then tested for mercury concentration in duplicates using the Perkin Elmer Flow Injection Mercury System (FIMS 100).

\section{Veterinary drug residue testing}

ELISA screening for CAP, MG and GV: Competitive ELISA based in-vitro screening was used to detect the presence of CAP, MG and GV in the retail catfish nuggets according to USDA-FSIS Protocols [7,15]. This technique can detect CAP at concentration as low as $0.25 \mathrm{ppb}$ [15]. The catfish nuggets were processed to extract any CAP present in the sample and detected using the commercial ELISA kits purchased from BioControl (Bellevue, WA). The presence of MG/LMG and CV/ LCV was detected using commercial Malachite Green ELISA Kits purchased from BioScientific Corp (Austin, TX). The analysis is only capable of

\begin{tabular}{|c|c|c|c|c|c|c|c|c|}
\hline \multirow[t]{2}{*}{ Sample } & \multicolumn{2}{|l|}{ MG } & \multicolumn{2}{|l|}{ GV } & \multicolumn{2}{|l|}{ LMG } & \multicolumn{2}{|l|}{ LGV } \\
\hline & $\begin{array}{l}\text { Normalized } \\
\text { Area }\end{array}$ & $\begin{array}{l}\text { Calculated Concentra- } \\
\text { tion }(\mathrm{ng} / \mathrm{g})\end{array}$ & $\begin{array}{l}\text { Normalized } \\
\text { Area }\end{array}$ & $\begin{array}{l}\text { Calculated Concentra- } \\
\text { tion }(\mathrm{ng} / \mathrm{g})\end{array}$ & $\begin{array}{l}\text { Normalized } \\
\text { Area }\end{array}$ & $\begin{array}{l}\text { Calculated } \\
\text { Concentration } \\
\text { (ng/g) }\end{array}$ & $\begin{array}{l}\text { Normalized } \\
\text { Area }\end{array}$ & $\begin{array}{l}\text { Calculated } \\
\text { Concentration } \\
\text { (ng/g) }\end{array}$ \\
\hline Catfish 1 & 0.0000 & & 99,200 & 0.86 & 0.0039 & 0.007 & 0.0693 & 0.05 \\
\hline Catfish 2 & 0.0000 & & 12,100 & 0.08 & 0.0000 & & 0.0330 & 0.01 \\
\hline Catfish 3 & 0.0120 & 0.0659 & 15,490 & 0.11 & 0.0000 & & 0.0101 & -0.01 \\
\hline Catfish 4 & 0.0052 & 0.0591 & 10,170 & 0.06 & 0.0000 & & 0.0052 & -0.02 \\
\hline Catfish 8 & 0.0045 & 0.0584 & 126,200 & 1.1 & 0.0051 & 0.009 & 0.0776 & 0.06 \\
\hline
\end{tabular}

Table 1: Confirmation results on presumptive dye-positive samples by HPLC-MS/MS 


\begin{tabular}{|l|l|l|l|l|l|l|l|}
\hline S.No & Sample ID & CAP & MG+GV & $\begin{array}{l}\text { Arsenic } \\
(\mathbf{p p b})\end{array}$ & $\begin{array}{l}\text { Lead } \\
\mathbf{( p p b )}\end{array}$ & $\begin{array}{l}\text { Cadmium } \\
\mathbf{( p p b )}\end{array}$ & $\begin{array}{l}\text { Mercury } \\
\mathbf{( p p b )}\end{array}$ \\
\hline 1 & $427-2$ & Negative & Negative & 0 & 0 & 10.00 & 0 \\
\hline 2 & $87-4$ & Negative & Negative & 0 & 0 & 0 & 0 \\
\hline 3 & S523-1 & Negative & Negative & 0 & 0 & 71 & 0 \\
\hline 4 & SR17 & Negative & Negative & 0 & 0 & 12.23 & 0 \\
\hline 5 & PC 9 & Negative & Negative & 0 & 0 & 14.68 & 0 \\
\hline 6 & S517-8 & Negative & Negative & 0 & 0 & 0 & 0 \\
\hline 7 & $546-3$ & Negative & Negative & 0 & 0 & 0 & 0 \\
\hline 8 & S425-2 & Negative & Negative & 0 & 0 & 0 & 0 \\
\hline 9 & $535-12$ & Negative & Negative & 0 & 0 & 151.0 & 0 \\
\hline 10 & $536-3$ & Negative & Negative & 0 & 0 & 0 & 0 \\
\hline 11 & S425-4 & Negative & Negative & 0 & 0 & 0 & 0 \\
\hline 12 & $535-1$ & Negative & Negative & 0 & 0 & 0 & 0 \\
\hline 13 & $535-7$ & Negative & Negative & 0 & 0 & 12.31 & 0 \\
\hline 14 & $725-3$ & Negative & Negative & 0 & 0 & 0 & 406.1 \\
\hline 15 & SR-11 & Negative & Negative & 0 & 0 & 0 & 0 \\
\hline 16 & $536-4$ & Negative & Negative & 0 & 0 & 0 & 0 \\
\hline 17 & PC4 & Negative & Negative & 0 & 0 & 18.63 & 0 \\
\hline 18 & S573-1 & Negative & Negative & 0 & 0 & 0 & 0 \\
\hline 19 & $445-1-N$ & Negative & Negative & 0 & 0 & 0 & 0 \\
\hline 20 & $70-590$ & Negative & Positive & 0 & 0 & 48.07 & 0 \\
\hline 21 & S558 & Negative & Negative & 0 & 0 & 0 & 0 \\
\hline 22 & 70594 & Negative & Negative & 0 & 0 & 0 & 0 \\
\hline 23 & S580 & Negative & Negative & 0 & 0 & 29.55 & 0 \\
\hline 24 & S589 & Negative & Negative & 0 & 0 & 0 & 0 \\
\hline & & & & & 0 & \\
\hline & & & 0 & 0 & 0 \\
\hline
\end{tabular}

Table 2: Results of ELISA screening and heavy metal testing for catfish nuggets.

\begin{tabular}{|l|l|l|l|l|l|}
\hline $\begin{array}{l}\text { Heavy } \\
\text { metal }\end{array}$ & $\begin{array}{l}\text { Range } \\
\text { (ppb) }\end{array}$ & $\begin{array}{l}\text { Mean con- } \\
\text { centration } \\
\text { in nugget } \\
\text { samples } \\
\text { (ppb) }\end{array}$ & $\begin{array}{l}\text { Number of } \\
\text { samples with } \\
\text { detectable } \\
\text { levels of } \\
\text { heavy metal }\end{array}$ & $\begin{array}{l}\text { Percent } \\
\text { samples with } \\
\text { detectable } \\
\text { heavy metals } \\
(\%)\end{array}$ & $\begin{array}{l}\text { Action Level } \\
\text { in Seafood } \\
\text { (ppb) }\end{array}$ \\
\hline Arsenic & 0 & 0 & 0 & 0 & $76000-86000$ \\
\hline Lead & 0 & 0 & 0 & 0 & $1500-1700$ \\
\hline Cadmium & $0-151.0$ & 15.31 & 9 & 37.5 & $3000-4000$ \\
\hline Mercury & $0-406.1$ & 16.92 & 1 & 4.16 & 1000 \\
\hline
\end{tabular}

Table 3: Mean concentrations and range $(\mathrm{ppb})$ of heavy metals in the catfish nuggets.

giving results that are a total sum of concentrations of MG, LMG, CV and LCV. The ELISA analysis is not capable of differentiating between these four compounds [16]. This ELISA analysis is capable of detecting the total concentrations more than $1 \mathrm{ppb}$ [7]. The ELISA analysis was conducted in duplicate according to the manufacturer specifications for the ELISA kits, and included both positive (10 ppb of the drug residues) and negative controls. Samples which were tested presumptive positive for the veterinary drugs were then subjected to confirmatory testing for both the presence and absence of the drugs as described below.

HPLC-MS/MS confirmation for MG, CV, and LMG, and LCV: Presumptive positive samples from ELISA screening was confirmed by HPLC-tandem mass spectrometry based on a standard European Union (EU) method originally developed in Fougères Laboratory, the French Agency for Food, Environment and Occupational Health Safety (ANSES) [17]. Both confirmation and quantification were fulfilled using deuterated internal standards. LC analysis was carried out using an Agilent 1100 liquid chromatograph system. A Prodigy ODS-3 (3 $\mu \mathrm{m}, 100 \mathrm{~mm} \times 2.0 \mathrm{~mm}$ ) C18 column (Phenomenex, Torrance, CA) was used at $30^{\circ} \mathrm{C}$ with a $\mathrm{C} 18$ Security Guard ODS $(4.0 \times 2.0 \mathrm{~mm})$ guard column (Phenomenex).The detector was an Applied Biosystems/MDS SCIEX API 3000TM triple-quadrupole mass spectrometer (Concord,
Ontario, Canada) equipped with an electrospray ionization (ESI) source and controlled by Analyst 1.5 software (Table 1).

\section{Results and Discussion}

The results from heavy metal testing for individual samples are listed in table 2. The summary of the results are listed in table 3 . The proficiency levels of detection for those compounds using the AA method are Hg-200 ppb, As-200 ppb, Pb-25 ppb, Cd-10 ppb [18,19]. Of the 24 catfish nugget samples tested none had detectable levels of $\mathrm{Pb}$ or As. Nine (37.5\%) of the catfish nuggets had detectable levels of Cd, and while the FDA has no action limits established for Cd levels in fish, the action levels are well below the guidelines set for crustacean and shellfish (3000-4000 ppb) [20]. All nine samples which had detectable levels of Cd were well below FDA guidance levels for seafood. Of the catfish nuggets which were tested for the presence of $\mathrm{Hg}$, one sample had detectable a detectable level of that contaminant ( $406 \mathrm{ppb}$ ), which was below the action limit established by the FDA for mercury in fish of $1000 \mathrm{ppb}$ [20]. The levels of the heavy metals in the catfish nuggets, if any, were well below levels of concern as determined by the FDA and were within the ranges found in previous studies for catfish and other seafood.

In the proposed rule for inspection of catfish and catfish products the USDA FSIS discusses a number of studies that have been conducted to determine the incidence and prevalence of heavy metal residues in catfish from retail outlets in the US $[18,19]$. Of 737 catfish samples collected in 2008 and 2009 seventeen (2.31\%) had detectable levels of heavy metals, two of which $(0.27 \%)$ had detectable levels of Cd [18]. Between 2010 and 2011 twenty of 741 catfish samples (2.71\%) had detectable (non-violative) levels of heavy metals [19]. Ten of the catfish samples (1.35\%) had detectable levels of Cd while ten had detectable levels of $\mathrm{Pb}$, and none had detectable levels of $\mathrm{Hg}$ [19]. The differences in detectable levels of heavy metals in catfish samples may be due to the products tested.

In addition to heavy metals, the catfish nuggets were also tested for the presence of banned veterinary drugs including malachite green, gentian violet, and chloramphenicol (Table 1). No nugget sample tested positive for chloramphenicol using the ELISA test. The ELISA screening analysis identified a total of five catfish nuggets as presumptive positive for the presence of MG and GV. They were then subjected to confirmation by HPLC-MS/MS. All samples were confirmed negative except one (catfish 8) with GV at $1.1 \mathrm{ng} / \mathrm{g}$, slightly higher than the FDA action level of $1 \mathrm{ng} / \mathrm{g}$ (Table 1). The lack of its metabolite, LGV, in the same sample, however, indicated this higher reading most likely originated from post-process contamination. It is documented that if MG is absorbed into animal body, intestinal microfloras will extensively reduce MG to LMG [20]. Consequently, leuco metabolites are the focus of regulatory program. In this work, matrix effects were overcome by using deuterated internal standards leading to reliable quantitation. Due to the excellent resolution of HPLC-MS/MS technique, presence of GV in a sample was unambiguously identified. Based on the fact that GV is known to be an ingredient of black ink, a possible source of contamination is the black marker often used to label plastic sample bags or supermarket packaging and labels.

Catfish products sold in the U.S. can be sold as fillets, strips, steaks, and nuggets. Retail studies have typically focused on final products such as fillets. Nuggets are the fatty belly flap that are typically removed from the fillet during processing [21] and represent a different retail product. When catfish nuggets were tested the levels of heavy metals was well below guidance and action levels specified for seafood, and 
Citation: Ozbay G, Babu BK, Chen G (2013) Prevalence of Veterinary Drug Residues and Heavy Metals in Catfish Nuggets. J Food Process Technol S11-005. doi:10.4172/2157-7110.S11-005

Page 4 of 4

the only sample which tested positive for a veterinary drug residue may have been due to post-process contamination. We believe the research results discussed in this paper will be beneficial for the seafood industry and consumers and will help the regulatory agencies to make informed decision.

\section{Acknowledgements}

Special thanks to Drs. Kathleen Rajkowski and Christopher Sommers at USDA-ARS-ERRC for their contribution and suggestions throughout the project without their support, this project would not be completed. We would like to thank the undergraduate research assistants, Ms. Eunice Handy and Ms. Orirat Badru at Delaware State University for their assistance preparing and analyzing the samples in this research project. We would like to thank Dr. Steven Lehotay and his lab personnel for their support and training they provided for using ELISA Screening for the drug residues and Dr. Lynn Cruickshank and other scientists at the USDAFSIS Lab in Athens, GA for their training and guidance with the ELISA Screening and heavy metal testing. This project is funded by USDA and Delaware State University.

\section{References}

1. New York Times (2007) F.D.A. Issues Alert on Chinese Seafood.

2. USDA-NASS (U. S. Department of Agriculture, National Agriculture Statistics Service) (2006) Catfish Processing. Agricultural Statistics Board, Washington DC.

3. NFS. National Fisheries Institute (2012) Top 10 Consumed Seafoods. Retrieved January 17.

4. USDA-NASS (U. S. Department of Agriculture, National Agriculture Statistics Service). 2011. Catfish Processing. Agricultural Statistics Board, Washington D. C.

5. FDA (2009) U. S. Food and Drug Administration. Import Refusal Report.

6. Liang F, Hu P, Li P (2006) Determining Malachite Green and Leuco-malachite Green in Food by LC/MS/MS. Agilent Technologies. Beijing, China.

7. USDA-FSIS, Office of Public Health Service (2010) CLG-MG/CV1.00 Screening for Malachite Green and Crystal Violet by ELISA (Draft) 1-13.

8. Littlefield NA, Blackwell BN, Hewitt CC, Gaylor DW (1985) Chronic toxicity and carcinogenicity studies of Gentian Violet in mice. FundamApplToxicol 5: 902 912

9. Wan H, Weng S, Liang L, Lu Q, He J (2011) Evaluation of the developmental toxicity of leucomalachite green administered orally to rats. Food ChemToxicol 49: 3031-3037.

10. IARC. International Agency for Research on Cancer (1990) Chloramphenicol Summaries and Evaluations 50: 169

11. USDA FSIS (2011) Mandatory inspection of catfish and catfish productsproposed rule. Fed Reg 76: 10434-10469.

12. USDA-FSIS, Office of Public Health Service (2010) CLG-TM1.01. Trace Metals

13. USDA-FSIS, Office of Public Health Service (2010). CLG-ARS1.04 Determination of Arsenic by Atomic Absorption Spectroscopy: 16.

14. USDA-FSIS, Office of Public Health Service (2010) CLG-MERC1.00 Determination of Mercury in Catfish (Draft) 12.

15. USDA-FSIS, Office of Public Health Service (2010) CLG-CAM1.01 Screening for Chloramphenicol by ELISA (Draft) 1-2.

16. Hurtaud-Pessel D, Couëdor P, Verdon E (2011) Liquid chromatographytandem mass spectrometry method for the determination of dye residues in aquaculture products: Development and validation. J. Chromatogr. A 1218 $1632-1645$.

17. USDA FSIS. 2011. 2009-2010: Analysis of heavy metals and veterinary drugs in 737 catfish samples from retail markets in the United States.

18. USDA FSIS. 2011. 2009-2010: Analysis of heavy metals and veterinary drugs in 741 catfish samples from retail markets in the United States.

19. US FDA (2011) Appendix 5 - FDA \& EPA Safety Levels in Regulations and Guidance - 3rd Edition.

20. Henderson AL, Schmitt TC, Heinze TM, Cerniglia CE (1997) Reduction of malachite green to leucomalachite green by intestinal bacteria. Appl Environ Microbiol 63: 4099-4101.

21. Silva J, Dean S (2001) Processed catfish: product forms, packaging, yields and product mix. Southern Regional Aquaculture Center. SRAC Publication No. 184.
This article was originally published in a special issue, Catfish Safety handled by Editor(s). Dr. Christopher H Sommers, EUSDA's Eastern Regiona Research Center, USA 